\title{
Prospective care of heart failure in Japan: lessons from CHART studies
}

\author{
Nobuyuki Shiba $\cdot$ Hiroaki Shimokawa
}

Received: 21 April 2011 / Accepted: 20 June 2011 /Published online: 9 July 2011

(C) European Association for Predictive, Preventive and Personalised Medicine 2011

\begin{abstract}
There are approximately 23 million patients with heart failure (HF) worldwide. The prognosis of patients with HF is still poor and a prospective approach for preventing and treating HF is necessary. The number of HF patients in Japan has been increasing since 1950 mainly because of a rapidly aging population. Furthermore, westernized dietary pattern, reduced physical activity, and obesity have become prominent, particularly in younger Japanese men. There is an increasing trend of diabetes and dyslipidemia, and the prevalence of smoking and hypertension continues to remain high. One of the largest HF cohorts in Japan, the CHART Studies, showed that coronary artery disease (CAD) was the most frequent etiology of HF currently. Thus, prospective strategies including accurate risk stratification, effective prevention of disease progression through evidence-based treatments, optimally personalized treatment particularly in elderly individuals, and life-long control of CAD risk factors are required to manage HF in Japan.
\end{abstract}

Keywords Prevention $\cdot$ Personalized medicine $\cdot$ Coronary artery disease $\cdot$ Cardiovascular risks $\cdot$ Elderly .

Undertreatment

N. Shiba $(\bowtie) \cdot$ H. Shimokawa

Department of Cardiovascular Medicine, Tohoku University

Graduate School of Medicine,

1-1 Seiryo-machi, Aobaku,

Sendai 980-8574, Japan

e-mail:nshiba@cardio.med.tohoku.ac.jp

N. Shiba $\cdot$ H. Shimokawa

Department of Evidence-based Cardiovascular Medicine,

Tohoku University Graduate School of Medicine,

1-1 Seiryo-machi, Aobaku,

Sendai 980-8574, Japan

\section{Worldwide increase in the number of patients with heart failure: importance of a prospective approach}

Chronic diseases such as heart disease, stroke, cancer, chronic respiratory diseases, and diabetes mellitus (DM) are the leading causes of morbidity and mortality worldwide [1]. Patients with such diseases account for approximately twothirds of all healthcare expenses. Typical medical intervention for patients with chronic diseases usually occurs during the latter stages of disease progression and the long-term prognosis remains poor despite the high costs of care. Healthcare systems in the developed countries are now changing their orientation from a disease-based approach to a prospective approach thereby focusing on predictive, preventive, and personalized medicine [2]. A key feature of such new approaches is strategic and personalized health planning. This includes new abilities to detect disease at an earlier stage, identify individuals at a higher risk of certain diseases, prevent disease progression, reduce healthcare costs, and ensure optimal treatment for each patient.

Heart failure (HF) is a complex syndrome that can result from structural or functional cardiac disorders. There has been an increase in the number of HF patients in the developed and developing countries. There are approximately 23 million patients with $\mathrm{HF}$ worldwide and 2 million patients are newly diagnosed with HF every year [3]. In the USA, the prevalence of HF in 2007 was 5.7 million and approximately 1 in 9 death certificates mentioned HF as the cause of death [4]. Furthermore, there were 670,000 new cases each year, with approximately 1 million hospitalizations due to worsening HF. The estimated healthcare cost of HF in 2010 was US $\$ 39.2$ billion [3, 4]. Although the epidemiology of HF in most developing countries is poorly established, an increase in the importance of cardiovascular diseases (CVD) as well as coronary 
artery disease (CAD), in such countries may lead to an increased incidence and prevalence of HF in the future [5].

Otherwise, the mortality rates due to CVD have been declining in North America, Europe, Australia, and New Zealand since decades. However, mortality rates have been increasing in the former Eastern Bloc countries, Latin and South America, India, China, and Africa [5]. The reasons for the increasing trend of HF worldwide are: (i) advancement in the control of infectious, parasitic, and nutritional diseases in developing countries, which has led to CVDs being increasingly recognized (ii) more people can reach the age at which CVDs manifest (especially in developed countries) (iii) HF usually develops at the final stage in the long-standing process of CVD.

The prevalence of CVD in Japan remains low. The ageadjusted mortality (standardized mortality rate in the Japanese population in 1985) from heart diseases has been declining recently. However, Japan has the most advanced aging society in the world and the crude number of patients who die as a result of heart diseases (of which the major part was considered to be HF) has been increasing dramatically for decades $[6,7]$. We have been conducting a multicenter prospective cohort study of HF patients named the Chronic Heart Failure Analysis and Registry in the Tohoku District (CHART-1; $N=$ 1278) since 2000. We reported that the mortality rate of HF patients in Japan was high and was comparable with that seen in the Western countries $[8,9]$.

Guidelines for the diagnosis and management of HF in adults set by the American College of Cardiology (ACC) Foundation / American Heart Association (AHA) have proposed a new classification of HF consisting of stages A, $\mathrm{B}, \mathrm{C}$, and $\mathrm{D}$ to emphasize the development and progression of HF [10]. Stage-A and -B patients are defined as those with risk factors that clearly dispose toward the development of HF. Stage C denotes patients with current or past symptoms of HF. Stage D denotes patients with truly refractory HF (Fig. 1). This classification shows that there are established risk factors and structural prerequisites for the development of HF. It also shows that the therapeutic interventions introduced even before the manifestation of structural disorders or symptoms can improve the prognosis of HF. Other authoritative HF guidelines published by organizations in several other developed countries have also underscored the importance of thorough care of patients at high risk of developing $\mathrm{HF}$ in addition to appropriate treatment for those with overt HF [10-13].

We started a new cohort named the CHART-2 Study in 2006 which included patients at high risk of developing HF as well as those with overt HF, and recently closed the entry period of the study [14]. This review summarizes the recent trends involved in development or exacerbation of HF in Japan as well as the clinical characteristics of Japanese patients with HF. Furthermore, we underscore the importance of a prospective approach in treating patients with CVD or those with a risk of developing HF in order to improve the prognosis of such patients.

\section{The declining birthrate and aging population in Japan}

The population of Japan surpassed 100 million in 1967 but the population growth has recently slowed. The annual growth of the population from 1960 to 1980 was approximately $1 \%$. However, the population of Japan began to decrease since 2005, and the total population in 2009 was 127.51 million [7]. The age structure diagram of 1950 shows that Japan had a standard-shaped pyramid characterized by a broad base. However, it represents a constrictive pyramid in 2009 , which indicates lower percentage of younger population and longer life expectancy (Fig. 2). In 2009 , the population of individuals aged $\geq 65$ years was 29.01 million, constituting $22.7 \%$ of the total population. In Japan, the rate of aging has been high since the 1970s compared with that in other Western or Asian countries; the percentage of elderly population ( $\geq 65$ years) is estimated to reach $39.6 \%$ by 2050 (Fig. 3) [15]. The mean life expectancy at birth in Japanese individuals continued to improve after World War II; it was 79.6 years for men and
Fig. 1 Stages in the development of heart failure [10]. HF, heart failure; MI, myocardial infarction; LVH, left ventricular hypertrophy; EF, ejection fraction

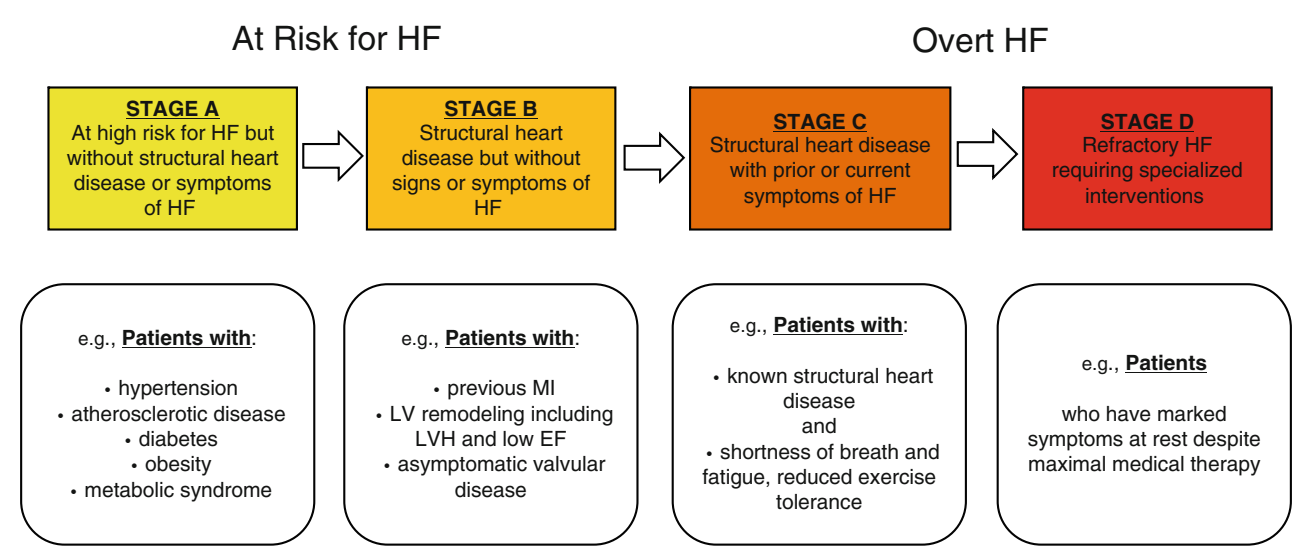


Fig. 2 Population pyramid of Japanese population in 1950 and 2009 [7]
1950

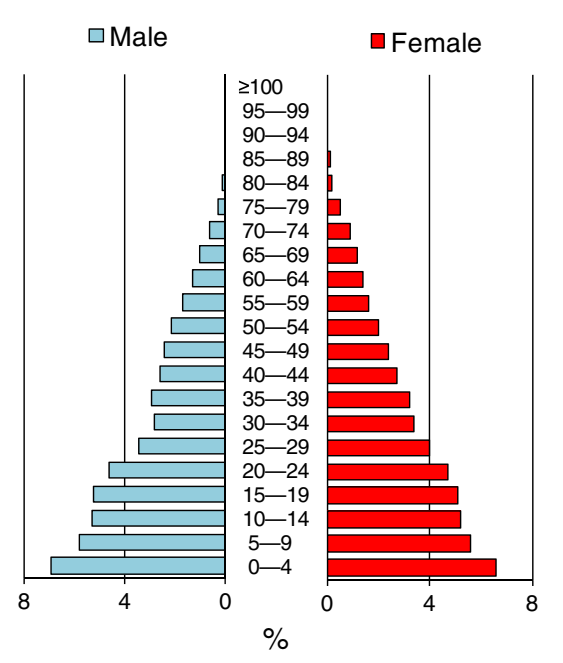

2009

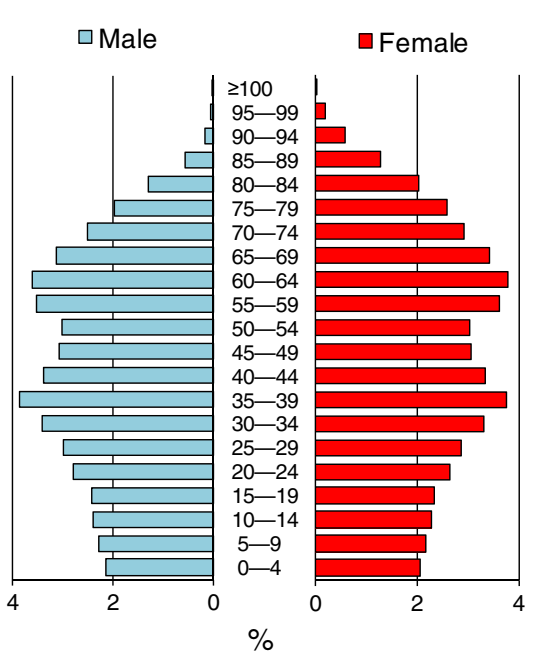

86.4 years for women in 2009 [7]. The percentage of younger age population ( $0-14$ years) has been decreasing since 1982 , which was $13.3 \%$ of the total population in 2009 [7]. The major reason for this declining trend is the recent low birth rate seen in the Japanese population, which was more prominent since the late 1970s. The birth rate in 2009 was as low as 8.5 per 1,000 population [7].

This trend showing a rapid increase in the elderly population will further increase the number of patients with CVD or HF. These patients would need a more personalized strategy in evaluation and treatment of disease compared with middle-aged patients (see below).

\section{"Lifestyle Westernization" among Japanese people}

Multiple dietary factors are strongly associated with atherosclerotic disease (including CAD) and appropriate diet modification can have beneficial effects. A common feature of the diets that help to prevent CAD is the emphasis on plant- based foods. These foods are characterized by a high intake of fiber and a low intake of saturated fat. Furthermore, in Japan, if the total fat intake is $>30 \% \mathrm{kcal}$, the predominant fat is monounsaturated fats [16]. Although the impact of these dietary patterns in the primary prevention of atherosclerotic disease is important, there are a few clinical trials that directly compare the effect of different diets on CVD risk.

The dietary pattern in Japanese individuals has changed with a higher intake of animal fat and protein, and a lower intake of carbohydrates [17]. The National Nutrition Survey of Japan (NNSJ) reported that the intake of dietary fat as a percentage of energy was approximately $8 \%$ in 1950 , which has rapidly increased by 3.8 -fold over the past 50 years [18]. In men and women, the mean total intake of calories in 2009 was $2073 \mathrm{kcal}$ and $1677 \mathrm{kcal}$, respectively, whereas percentage intake of energy as fat was $25.1 \%$ and $26.7 \%$, respectively. It is important to note that individuals aged $20-29$ years who were consuming $\geq 30 \%$ of total energy in the form of fats accounted for $37.0 \%$ men and $44.2 \%$ women [18].
Fig. 3 Trend of percentage of individuals aged $\geq 65$ years in various countries [15]

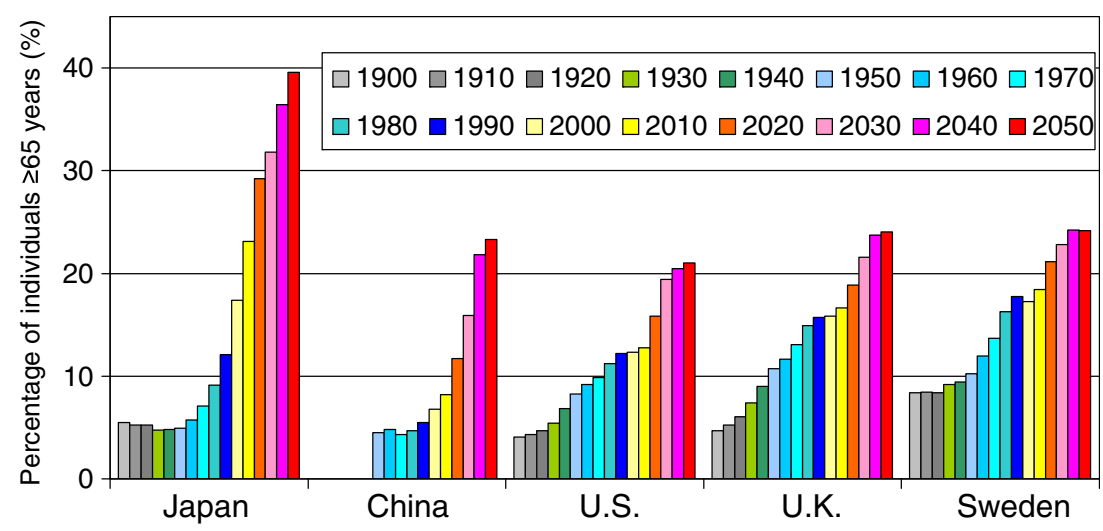


Studies have shown an inverse association between physical activity and the risk of developing CVDs such as CAD and stroke in men and women [19]. Meta-analyses of prospective observational studies revealed that moderately active men experienced $20-30 \%$ less age-adjusted rates of $\mathrm{CAD}$ and all-cause mortality compared with the least active men [20]. Regular physical activity of an adequate amount and intensity prevents the development of atherosclerosis and improves several cardiovascular risks which are causally linked to the progression of atherosclerosis (e.g., obesity, hypertension, dyslipidemia, diabetes, and smoking). Shibata et al. evaluated the relationship between physical activity and death from CVD using prospective data involving 12490 Japanese participants. They reported that more physical activity was associated with a reduced risk of death from CVDs [21]. The NNSJ showed an overall increase in the number of individuals who had regular exercise habits since 1987 (Fig. 4) [18]. However, a stable or decreasing trend of physical activity was prominent in men and women aged 20-39 years.

An increased intake of animal fat and relatively less physical activity in the younger Japanese population may have an impact on the development of CVD or HF. These findings warrant long-term monitoring of lifestyle and cardiovascular risks in those individuals.

\section{Trends in risks of CVD and HF in Japan}

Hypertension or raised blood pressure (BP) carries a definite risk of developing CVD. Successive lowering of BP will lead to cumulative reduction in the risk of developing CVD. Ueshima et al. reported the long-term trend of BP in a Japanese population using the NNSJ (which has been conducted since World War II) [6]. They reported that systolic blood pressure (SBP) showed a decline since 1965 in men aged $\geq 50$ years and in women of all age groups; the reduction in SBP for individuals aged $\geq 60$ years almost reached $\geq 15 \mathrm{mmHg}$ during 1965-2000. The

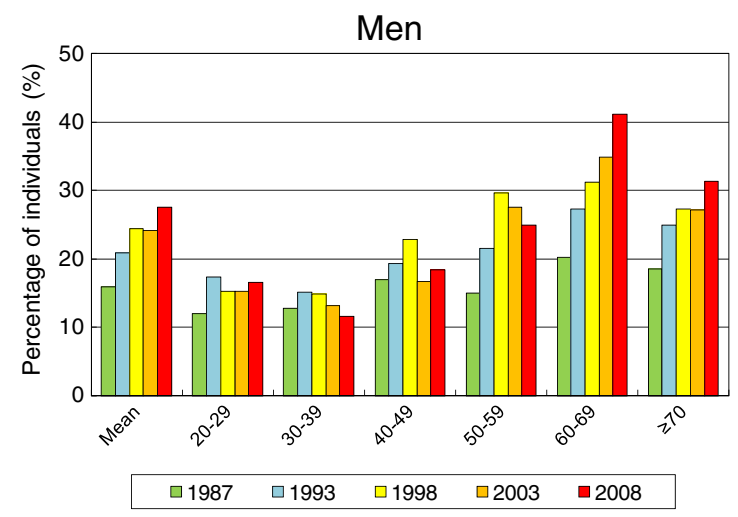

Fig. 4 Trend of regular exercise habit in Japanese individuals [18] prevalence of individuals with hypertension has also decreased since 1980 in all age groups (Fig. 5) [18]. There is clear evidence that increased consumption of salt is a major factor in increasing BP [22] and that the major reason for individuals showing decreasing trend for hypertension in Japan is due to reduced intake of salt. Salt consumption in northern Japan was $26-27 \mathrm{~g} /$ day in the 1950s; it decreased significantly to $13 \mathrm{~g} /$ day in 2001 and $11 \mathrm{~g} /$ day in 2008 [18].

However, Martiniuk et al. reported that the crude prevalence of hypertension in Japan in 2000 was $41.4 \%$ and $31.9 \%$ in men and women, respectively, and that the prevalence was the second highest in the WHO-defined Western Pacific and South-east Asian regions [23]. They reported that the sex-specific population-attributable fraction of fatal CAD attributable to hypertension was approximately $15 \%$ in men and $39 \%$ in women. The report of the Asia Pacific Cohort Studies Collaboration (APCSC) showed continuous log-linear associations between SBP and incidence of CAD [24]. A 10-mmHg decrease in SBP was associated with $46 \%, 24 \%$, and $16 \%$ lower CAD risk in individuals aged $<60,60-69$, and $\geq 70$ years, respectively. Further reductions in the prevalence of hypertensive individuals should be given high priority in many countries (including Japan) to prevent the development of hypertension-related CVD, which is a major cause of HF.

Individuals with DM are also at an increased risk of death from various types of CVDs. The APCSC analyzed 24 population-based cohort studies from Asia, Australia, and New Zealand [25]. This study included 29089 Japanese individuals (aged 20-96 years) and the mean prevalence of DM at study entry was $3.3 \%$. During a median follow-up of 5.4 years, they showed that age-, sex-, and study-adjusted hazard ratios (HRs) for fatal CAD associated with DM were 2.22 in the Asian population. In addition, there was no significant change in the HR after multivariable adjustment including BP, cholesterol, body mass index (BMI), and smoking status. It is important to note that the relative effect of DM on the risks of CVD and death in Asian populations

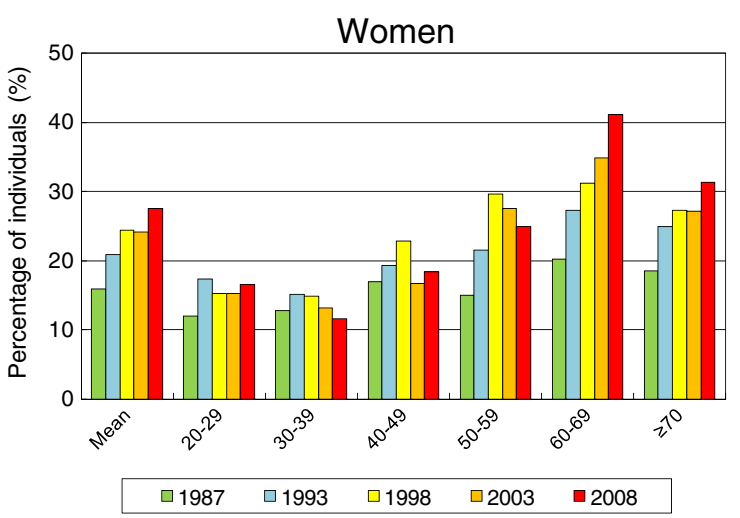



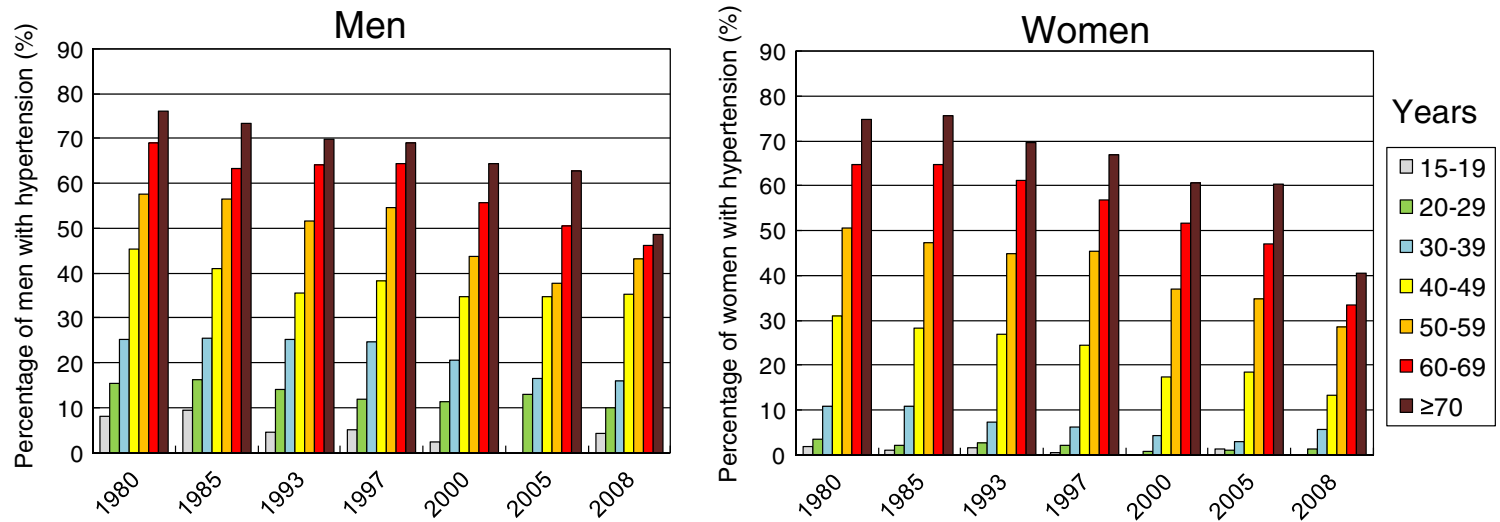

Fig. 5 Trend of percentage of individuals with hypertension by age [18]

was almost identical to that in Caucasian populations. The prevalence of DM has been increasing more rapidly throughout Asia compared with that in the Western countries. Wild et al. reported that individuals with DM in Japan would increase from 6.8 million in 2000 to 8.9 million in 2030 [26]. The NNSJ showed that the prevalence of individuals diagnosed as having DM or whose hemoglobin A1c level was $\geq 6.1 \%$ was $8.2 \%, 9.0 \%$, and $10.5 \%$ in the years 1997, 2002, and 2007, respectively [27]. This survey also revealed that the increase in prevalence was more prominent in individuals aged $\geq 60$ years and that 22.1 million Japanese people were considered to have DM (or the possibility of having glucose intolerance) in 2007 (Fig. 6).

Asian populations are less obese compared with Western populations. The BMI in Asians is approximately $20-24 \mathrm{~kg} / \mathrm{m}^{2}$, whereas it is $26-29 \mathrm{~kg} / \mathrm{m}^{2}$ in the Westerners [28]. However, age-adjusted BMI has increased since 1956 in the Japanese population [29]. The NNSJ revealed that the prevalence of Japanese male individuals with BMI $\geq 25 \mathrm{~kg} / \mathrm{m}^{2}$ has been
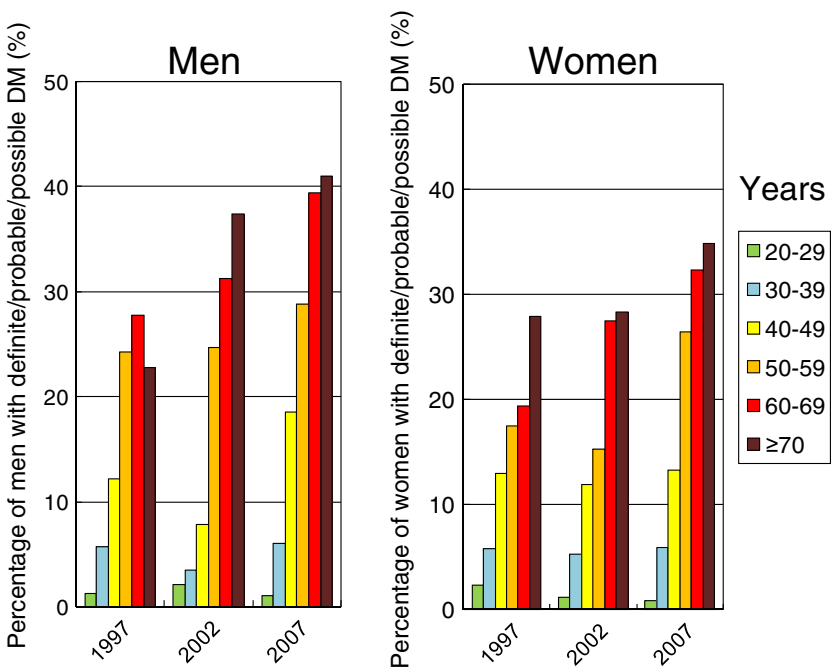

Fig. 6 Recent trend of percentage of individuals with DM by age [27]. DM, diabetes mellitus increasing (Fig. 7) and the mean prevalence was $16.8 \%$, $25.8 \%$, and $30.5 \%$ in the years 1979,1999 , and 2009 , respectively [18]. The BMI of Japanese women has been relatively stable for the last 30 years (Fig. 7) and the mean prevalence of Japanese females with a BMI $\geq 25 \mathrm{~kg} / \mathrm{m}^{2}$ was approximately $20 \%$ [18]. Increased BMI is also associated with raised $\mathrm{BP}$, glucose intolerance, dyslipidemia, and development of CVD in Japanese population. The analysis of NIPPON DATA showed that there was a significant doseresponse relationship between the BMI and odds ratio for hypertension in men and women [30]. This analysis also revealed that the percentage of individuals with hypertension attributable to obesity in 1980 and 1990 was $11.4 \%$ and $15.3 \%$ for men and $19.3 \%$ and $22.3 \%$ for women, respectively. Furthermore, Shiraishi et al. reported that a BMI $\geq 25 \mathrm{~kg} / \mathrm{m}^{2}$ was significantly associated with the development of acute myocardial infarction (AMI) in young and middle-aged Japanese men [31]. These findings suggest that obesity is now playing an important role in the development of cardiovascular risks and CVD in Japan.

Cigarette smoking has been associated with atherosclerotic disease (including CAD and stroke) throughout the world. The report of the APCSC in 2005 stated that 51$76 \%$ of men and $1-17 \%$ of women in Japan were current smokers from 1974 to 1997 [32]. This study revealed that the HR of current smokers for CAD was 1.60 compared with non-smokers in Asia, Australia, and New Zealand; there was a clear dose-response relationship between the number of cigarettes smoked per day and the incidence of CAD. The prevalence of smoking in Japanese men declined from $46.8 \%$ in 2003 to $38.2 \%$ in 2009 , whereas that in Japanese women is relatively lower compared with that in men, but remains high (11.3\% in 2003 and $10.9 \%$ in 2009) $[18,28]$. Martiniuk et al. reported that the fraction of CAD attributable to smoking in Japanese men and women in year 2000 was $22 \%$ and $7 \%$, respectively [33]. Smoking control must be more emphasized to reduce the prevalence of CVD in Japanese men and women. 

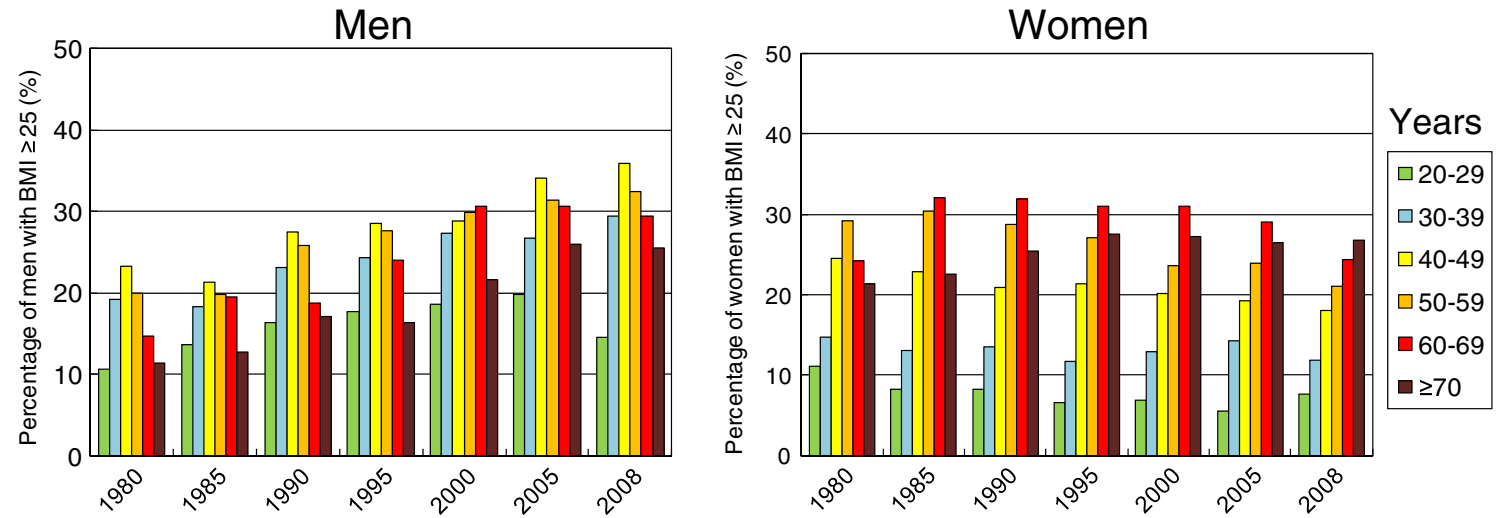

Fig. 7 Trend of percentage of individuals with BMI $\geq 25 \mathrm{~kg} / \mathrm{m}^{2}$ by age [18]. BMI, body mass index

Dyslipidemia is a well-established risk factor for CAD. Serum levels of total cholesterol (TC) in individuals of Asian countries (except Singapore) are generally far lower than those in the USA and other Western countries [28]. It was $<190 \mathrm{mg} / \mathrm{dL}$ in 1980 in all age groups, and has significantly increased in recent years $(>200 \mathrm{mg} / \mathrm{dL}$ in middle-aged men) (Fig. 8). However, the serum level of TC in the elderly Japanese population is lower than that of Western populations [34]. Although Japanese women aged 50-69 years showed a relatively high serum TC level (Fig. 8), the impact of raised TC or low-density lipoprotein cholesterol (LDL-C) between men and women might be different. Noda et al. after evaluating 91219 Japanese individuals without stroke and CAD, reported that a higher LDL-C level was associated with an increased risk of mortality from CAD in men but not in women [35]. Arai et al. evaluated the 40-year trend of lipid profiles in 12839 Japanese individuals [36]; they reported that the increase in TC level was attributed to an increase in the level of highdensity lipoprotein cholesterol, and not LDL-C. The triglyceride level in Japanese population increased over the last 10 years, which was mainly attributed to the
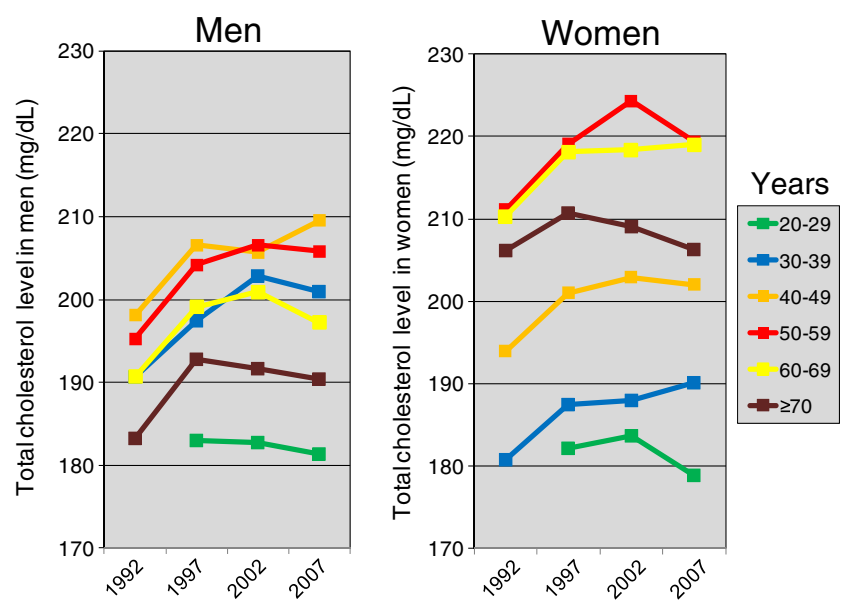

Fig. 8 Recent trend of total cholesterol level by age [18] increase of that in middle-aged men; the authors anticipate a further increase in the incidence of hypertriglyceridemia in the future. In Japan, high consumption of fish and rice have contributed in keeping the serum level of TC lower than that of Western countries [34, 37]. Recently, the intake of animal protein and fat in the Japanese population has increased significantly [38]. The impact of such alterations in dietary habits on the lipid profile should be evaluated.

\section{Trends in mortality and incidence of CAD in Japan}

Japan has the lowest mortality rate from CAD among the industrialized countries [19]. Mortality from CAD began to decline by 1970 in most countries. Age-adjusted mortality due to all heart diseases and CAD in Japan increased until 1970 and then continued to decrease gradually (Fig. 9) [7]. However, the crude mortality rate from all heart diseases, CAD other than AMI and HF has been increasing since the 1970s; crude mortality from AMI has decreased gradually since 1995 (Fig. 9). The major reason for such trends includes the rapidly aging Japanese society. The incidence rate of AMI was much lower than that in other industrialized countries [34]. Several reports from the USA showed a substantial decrease in CAD incidence beginning in 1970 $[39,40]$. However, it remains controversial whether the incidence rate of AMI in Japan has decreased or not. Kodama et al. evaluated the incidence of CAD from a 26-year follow-up study, which included 19961 subjects and reported that the age-adjusted incidence of AMI remained almost constant from 1958 to 1984 , averaging 2.1/1000 person-years in men and 0.79/1000 person-years in women [41]. Kitamura et al. reported an increasing trend of age-adjusted CAD incidence in Japanese men since 1980 in the rural and urban areas [42]. The Hisayama Study, using three study cohorts from 1961, 1974, and 1988, reported that the agestandardized incidence of $\mathrm{CAD}$ had been increasing in individuals aged $\geq 80$ years [43]. 

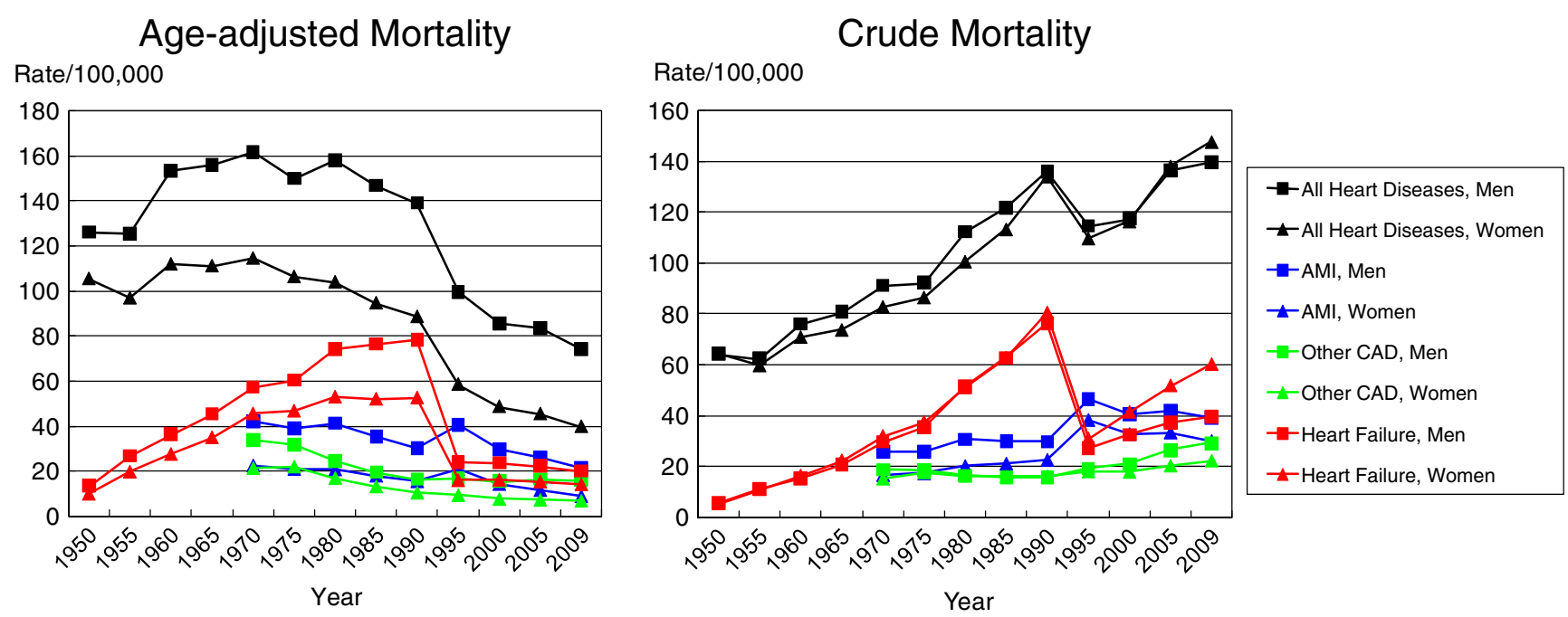

Fig. 9 Trend of mortality rate by various heart diseases [7]. AMI, acute myocardial infarction; CAD, coronary artery disease

The mechanisms of increasing trend of AMI in Japan include westernization of lifestyle, increased prevalence of $\mathrm{DM}$, increased levels of TC in serum, increased BMI in men, and a high prevalence of hypertension and smoking. Although the incidence rate of AMI in Japan remains low, aggressive reduction of such cardiovascular risks must be emphasized to prevent the development of AMI.

\section{Elderly individuals and CVD}

In general, atherosclerosis takes a long time to develop. Most elderly individuals have some degree of atherosclerosis, and $>80 \%$ of all cardiovascular deaths occur in individuals aged $\geq 65$ years [44]. In many countries, the mortality rate from CAD and stroke has been decreasing steadily since the late 1960s. However, the reduction in mortality has been particularly observed in middle-aged men; the elderly population has not shown a substantial decrease in cardiovascular mortality [44]. Statistical data from Japan have also shown a decreasing trend in the crude cardiovascular mortality rate across all age groups since 1990. However, since 1950, there has been a dramatic increase in the mortality from heart diseases among individuals aged $\geq 75$ years and a moderate increase in the mortality from heart disease was observed in men aged 65-74 years (Fig. 10) [7]. The Tokyo Fire Department of the Fire and Disaster Management Agency in Japan sent 700808 ambulance services in 2010. It reported that the number of individuals aged $\geq 65$ years who utilized the service for a sudden illness was 277077 (39.5\%), which was an increase in the figure from 2003 (Fig. 11); one of the major reasons for this trend was the rapid increase in the elderly population in Tokyo [45].

Many of the elderly individuals are at a much higher cardiovascular risk than any other age group. However, the magnitude of risks and benefits of risk mitigation between the elderly and the younger or middle-aged population might be different.

Hypercholesterolemia or a high level of LDL-C is a major risk factor for developing $\mathrm{CAD}$ in the general population. However, in observational studies, this association in the older population is controversial [46]. One of reasons for the discrepancy in this association between middle-aged and older populations is that comorbidity is frequently observed in the elderly and this may cause acquired low levels of cholesterol. There were several reports showing that lipid-lowering treatment using 3hydroxy-3-methyl-glutaryl-CoA reductase inhibitors significantly reduced coronary events in the older age group similar to those in the middle-aged population in primary and secondary prevention trials $[46,47]$.

Hypertension is a definite risk factor for the development of CVD in the elderly population [48]. Many large prospective trials also documented the clear benefit of antihypertensive treatment in elderly patients with hypertension. A meta-analysis involving 5 trials in hypertensive patients aged $\geq 60$ years showed that antihypertensive agents resulted in a $19 \%$ reduction in CAD, which was similar to that seen in younger individuals [49]. Furthermore, Mulrow et al. reported that the short-term benefits in morbidity and mortality of treatment were greater in elderly than in younger patients [50]. The Hypertension in the Very Elderly Trial reported that antihypertensive treatment with indapamide in patients aged $\geq 80$ years was beneficial with significant reduction in death rate from cardiovascular causes or the development of HF [51].

Smoking is an established risk for the development of new CVDs in the elderly, although its relative contribution decreases with increasing age [52]. Furthermore, older people who cease smoking after 70 years of age showed a 

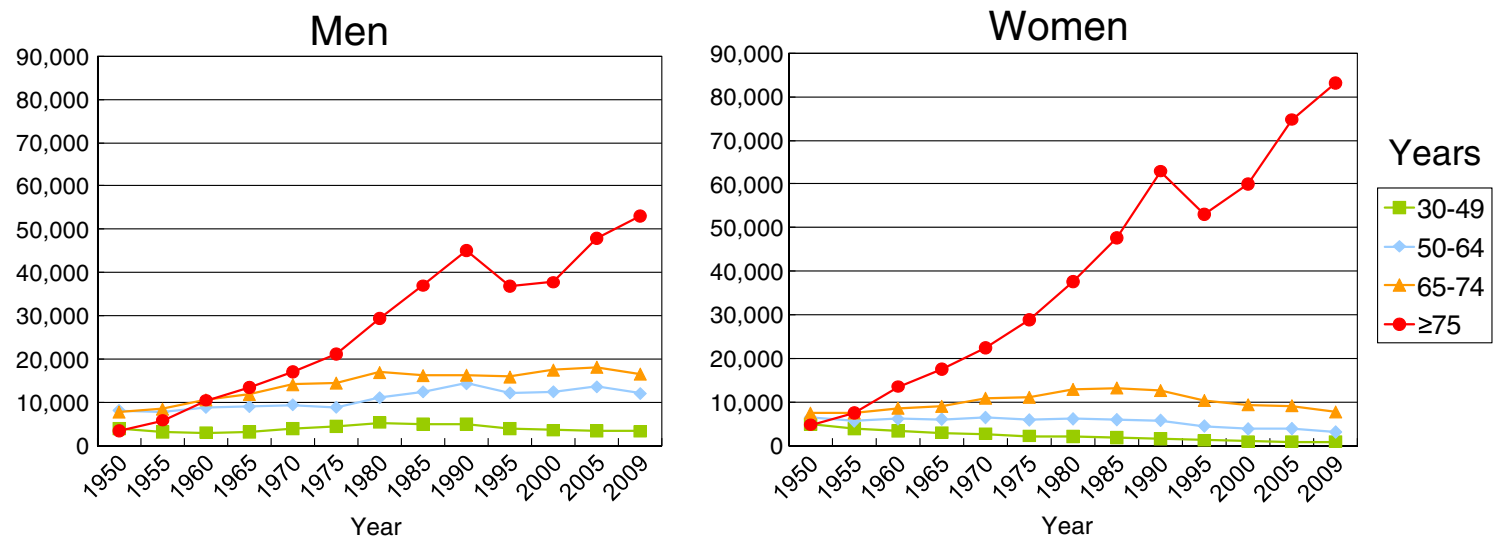

Fig. 10 Trend of number of individuals who died from heart diseases by age [7]

significant reduction in the development of new myocardial infarction or death [53].

DM or poor glycemic control are associated with an increased incidence of cardiovascular events in elderly men and women $[54,55]$. However, the relative effects of DM on CVDs are weaker among older patients compared with younger patients [56].

Atherosclerosis is not the only abnormality associated with the development of symptomatic CVD. Triggering factors (e.g., increased coagulation activity, increased activity of sympathetic nervous system, vasoactive hormone, smoking) which might be more frequently observed in elderly individuals also play an important role (especially in artery-occlusive diseases). The most effective strategies preventing the development of $\mathrm{HF}$ and the progression of CVD are reduction of modifiable cardiovascular risks and elimination of triggering factors that causes sudden arterial occlusion or decompensation of HF. However, undertreatment or insufficient control of cardiovascular risks may be more prominent in elderly patients. National Health

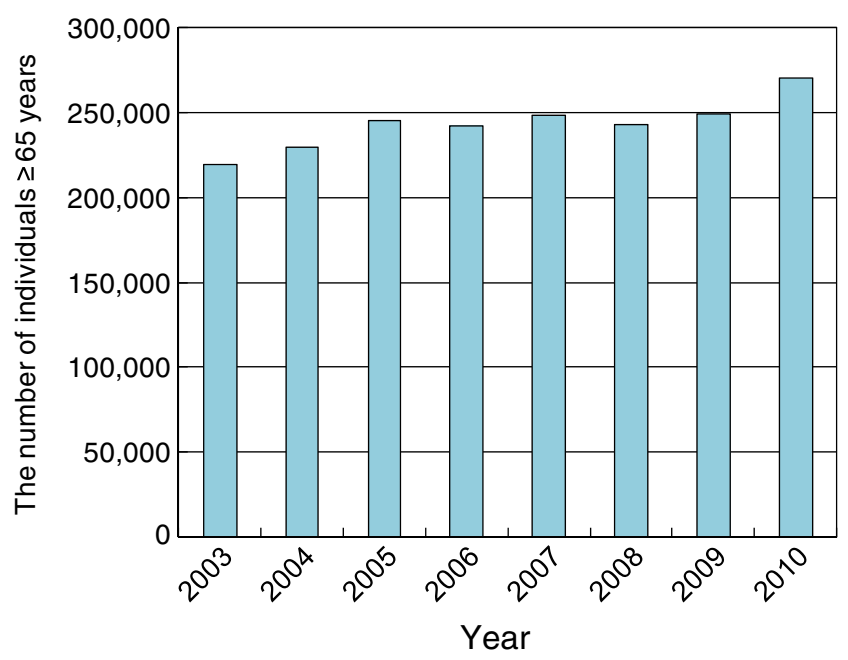

Fig. 11 Number of ambulance service in the Tokyo Fire Department [45] and Nutrition Examination Survey III showed that only 23 $46 \%$ of patients with hypertension aged $>70$ years showed adequate control of BP [57]. Our previous cohort study of HF patients: (the CHART-1 Study) revealed that the penetration rate of standard HF treatment such as reninangiotensin system (RAS) inhibitors and $\beta$-blockers was significantly lower in elderly patients, which was validated by multivariate logistic regression analyses [58].

Some elderly individuals have comorbidities that represent a significant association with CVD. Chronic kidney disease (CKD) is an extensive public-health problem and is observed in $9-13 \%$ of the general population [59]. The prevalence of $\mathrm{CKD}$ increases with age and many reports have clarified that CKD is an important risk factor for the development and worsening of CVD [59, 60]. Chronic obstructive pulmonary disease (COPD) is the fourth most frequent cause of death; approximately 400000 deaths occur each year from COPD in developed countries [61]. COPD is one of the persistent systemic inflammatory disorders (like CVD or HF) and is strongly associated with the elderly population (probably as a result of the long-term exposure to risk factors such as cigarette smoking) [61]. Recent reports showed that COPD was a significant risk factor for developing CVD and cardiovascular death. Mazza et al. reported that COPD was an independent risk factor for cardiovascular mortality in hypertensive individuals [62]. Kjøller et al. also revealed that COPD was a predictor of mortality in patients with AMI when evaluating 6669 subjects included in the Trandolapril Cardiac Evaluation Study [63]. Further research should be emphasized to evaluate such extra cardiac risks for CVD and to recognize novel prognostic risks (particularly in the elderly population).

The pathophysiology of CVD or HF is more complicated and heterogeneous in elderly patients. Furthermore, such patients usually have non-cardiovascular comorbidities (including chronic diseases) which sometimes complicate appropriate diagnosis and treatment. Conventional diagnostic tools may be less useful in such patients compared with 
younger or middle-aged patients. Importantly, there is no sufficient clinical evidence for treating elderly patients with CVD or HF. Thus a personalized approach is necessary in the prevention and management of HF in elderly patients.

\section{CHART-2 study}

The prevalence and crude mortality rate of CVD has been relatively lower in Japan compared with that in Western countries. However, it has been rapidly increasing due to the westernization of lifestyle, increased risk of atherosclerosis, and a rapidly aging population [7, 9]. Our previous cohort study of HF patients, the CHART-1 Study, revealed that the most prevalent etiology of HF in Japan was nonischemic cardiomyopathy (28.6\%) and only $25.4 \%$ of HF was attributed to CAD (which is the leading cause of HF in most Western countries) [8]. We started a multicenter prospective cohort study, the CHART-2 Study, in October 2006 to evaluate the clinical characteristics and prognosis of Japanese patients at high risk for disease progression of CVD or those with overt HF [14]. The study was conducted in collaboration with 24 hospitals in the Tohoku district; this is in the north-east of Japan and has a population of 9.8 million. Stable patients aged $\geq 20$ years were consecutively enrolled in the study who were suffering from CAD or were in stage $\mathrm{B}, \mathrm{C}$, or $\mathrm{D}$ as defined by the Guidelines for the Diagnosis and Management of HF in Adults of the ACC Foundation/AHA [10]. The entry period of the CHART-2 Study was closed in March 2010 ( $N=10219)$, which made this study the largest-scale cohort of CVD in Japan [64].
Characteristics of Japanese patients with CVD but without $\mathrm{HF}$

The CHART-2 cohort involved 5484 patients (53.7\%) with CVD but without HF. These patients were characterized by younger age (67.6 \pm 12.2 years), higher number of males $(71.0 \%)$, less severe symptom, and higher values of ejection fraction (EF, $65.5 \pm 11.7 \%$ ) compared with those in stage $\mathrm{C}$ or D. However, the prevalence of cardiovascular risks such as hypertension (75.4\%), DM (21.9\%), and dyslipidemia (72.7\%) was similarly high. The prevalence of current smokers was also high, $23.3 \%$ (men) and 5.9\% (women). CAD was the most prevalent etiology accounting for $58.2 \%$ of patients in stage B. Furthermore, B-type natriuretic peptide (BNP) level was mildly elevated in patients in this category $(97.6 \pm 188.1 \mathrm{pg} / \mathrm{mL})$ and $32.4 \%$ of patients had CKD. Usage rates of RAS inhibitors and $\beta$ blockers were $57.9 \%$ and $33.0 \%$, respectively.

HF stage progression and exacerbation in prognostic risks

Background characteristics of CHART-2 patients showed a graded appearance of HF stage on CVD severity [14]. For example, as the HF stage progressed from stage B to stage $\mathrm{D}$, left ventricular end-diastolic dimension increased, left ventricular EF decreased, and BNP level increased significantly (Fig. 12). Furthermore, recently underscored kidney-related risks were also exacerbated with progression of HF stage; the estimated glomerular filtration rate (GFR) decreased, hemoglobin level decreased, and the urine albumin creatinine ratio increased significantly (Fig. 13).
Fig. 12 LV dimension, EF, and BNP of CHART-1 and CHART-2 patients [14]. BNP, B-type natriuretic peptide; $\mathrm{CAD}$, coronary artery disease; Dd, diastolic dimension; EF, ejection fraction; $\mathrm{LV}$, left ventricular

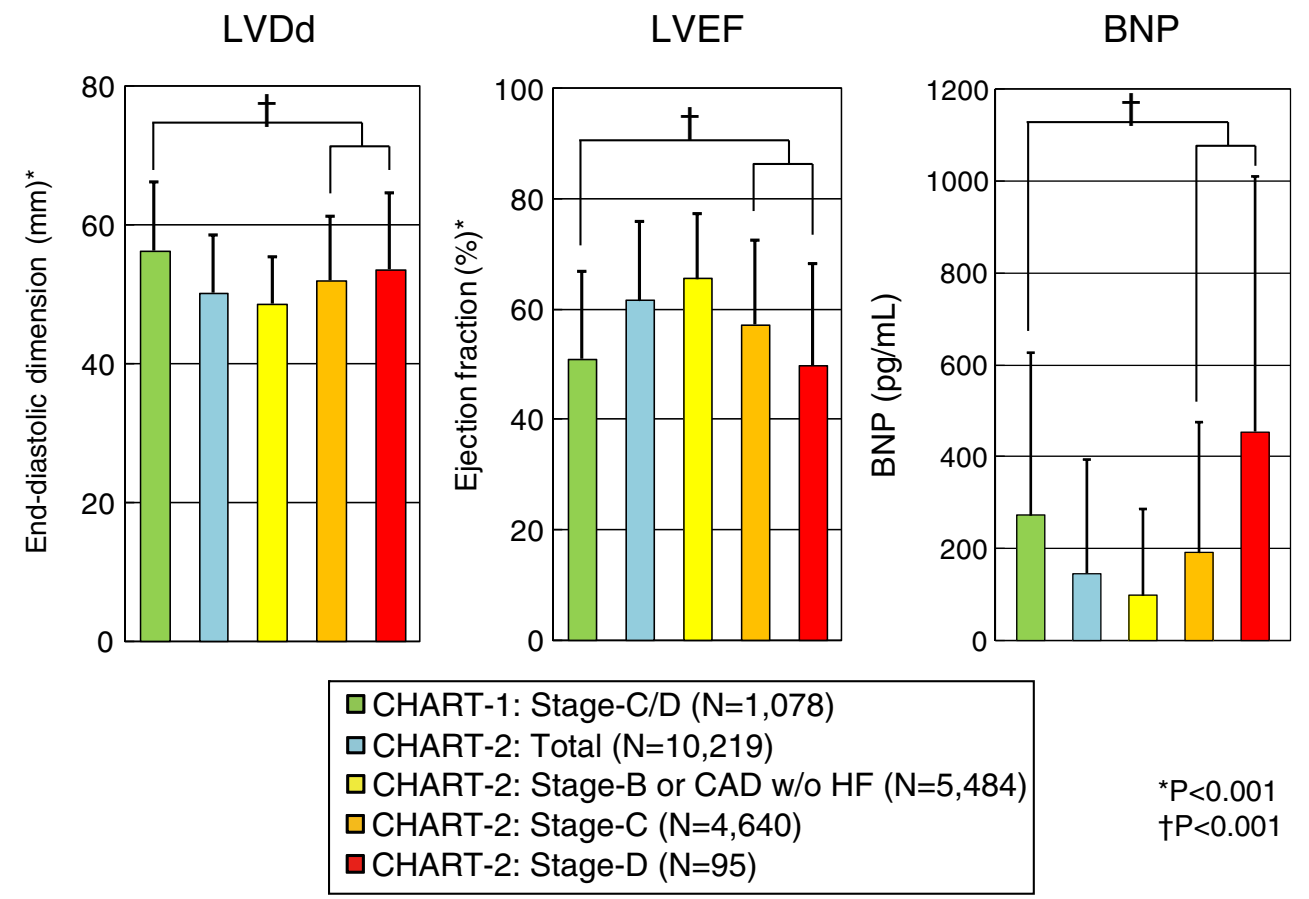


Fig. 13 GFR, hemoglobin lev$\mathrm{el}$, and urine albumin creatinine ratio of CHART-1 and CHART-2 patients [14]. CAD, coronary artery disease; GFR, glomerular filtration rate; UACR, urine albumin creatinine ratio
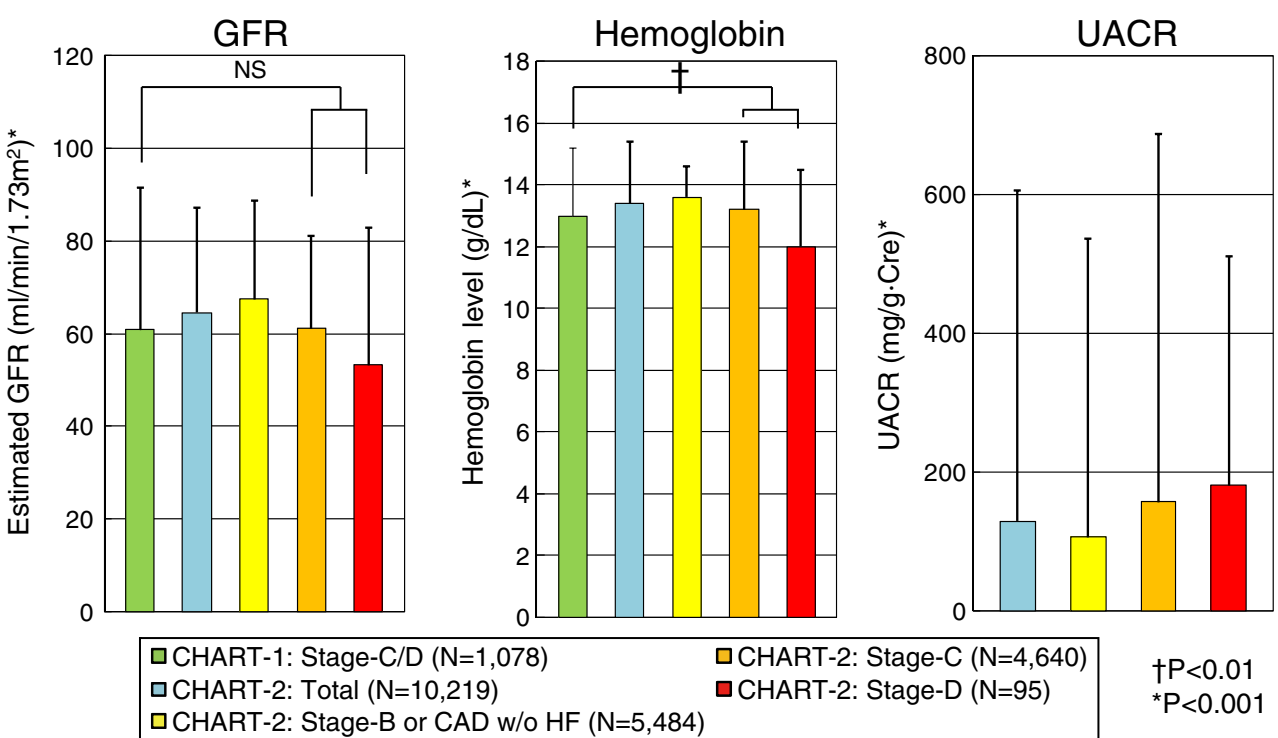

The accumulation of prognostic risks with HF stage included significant increases in age, heart rate, cardiothoracic ratio, and uric acid level, as well as significant decreases in BP, BMI, and LDL-C level [14].

Characteristics of Japanese patients with HF

The stage-C and -D groups, which were considered to be patients with overt HF, accounted for $45.4 \%$ and $0.9 \%$ of the total number of enrolled patients, respectively. The most prevalent etiology of HF in the CHART-2 Study was CAD (47.1\%) and it was almost comparable with the prevalence of HF etiology in Western observational cohort studies of HF (Fig. 14) [8, 65-69]. CAD as an etiology of HF has dramatically increased compared with that in the CHART-1 Study, which was undertaken approximately 6 years before the CHART-2 Study. The prevalence of hypertension and DM as comorbidities in CHART-2 patients was similar to that in Western studies (Fig. 15). Meanwhile, left ventricular EF at study entry was relatively higher and the prevalence of patients with preserved EF was considerably higher when HF patients in the CHART-2 Study were compared with those in studies of Western countries (Fig. 16). HF patients with preserved EF in the CHART-1 and -2 Studies were observed more frequently among elderly patients, just as in previous studies in Western countries $[14,58,68,69]$. Comparisons of the usage rates of medical treatments for HF patients are shown in Fig. 17. HF patients in the CHART-2 Study were characterized by lesser use of loop diuretics and a higher use of angiotensin-II receptor blockers, but usage of $\beta$-blockers and RAS inhibitors was similar compared with that in Western studies.
Fig. 14 Etiology of HF in Western patients and CHART patients [14]. Framingham, reference [65]; ADHERE, reference [66]; EHFS II, reference [67]; Owan, reference [68]; Bhatia, reference [69]; CHART1, reference [8]; CHART-2, reference [14]
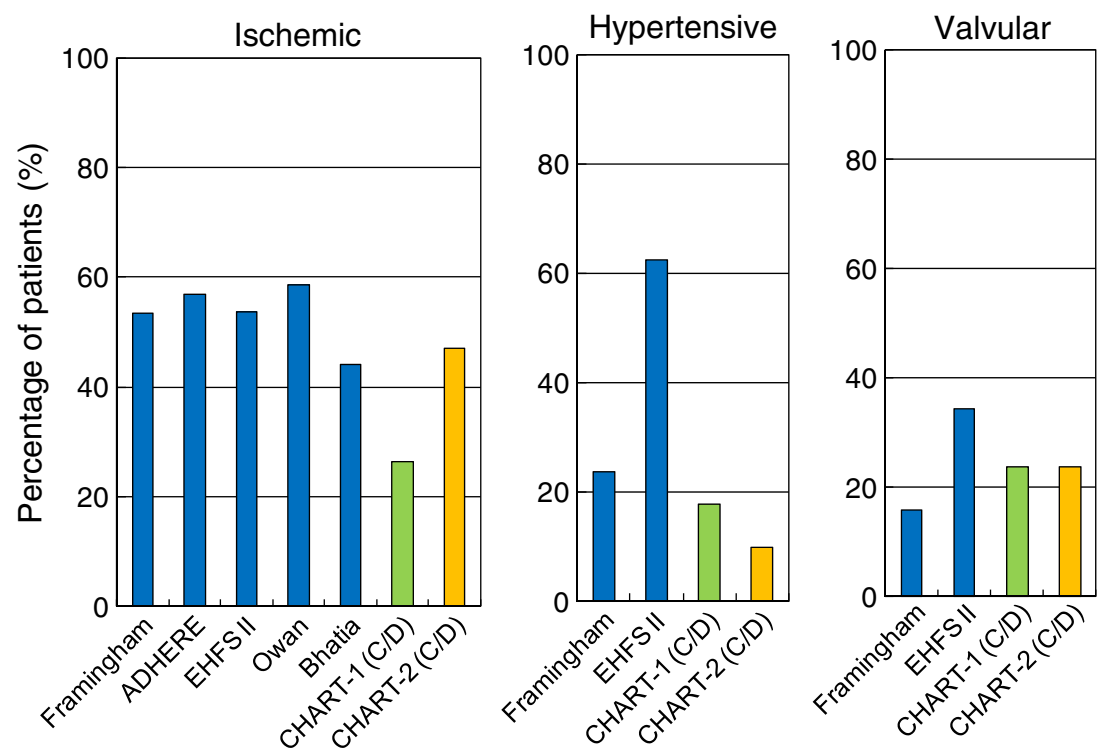

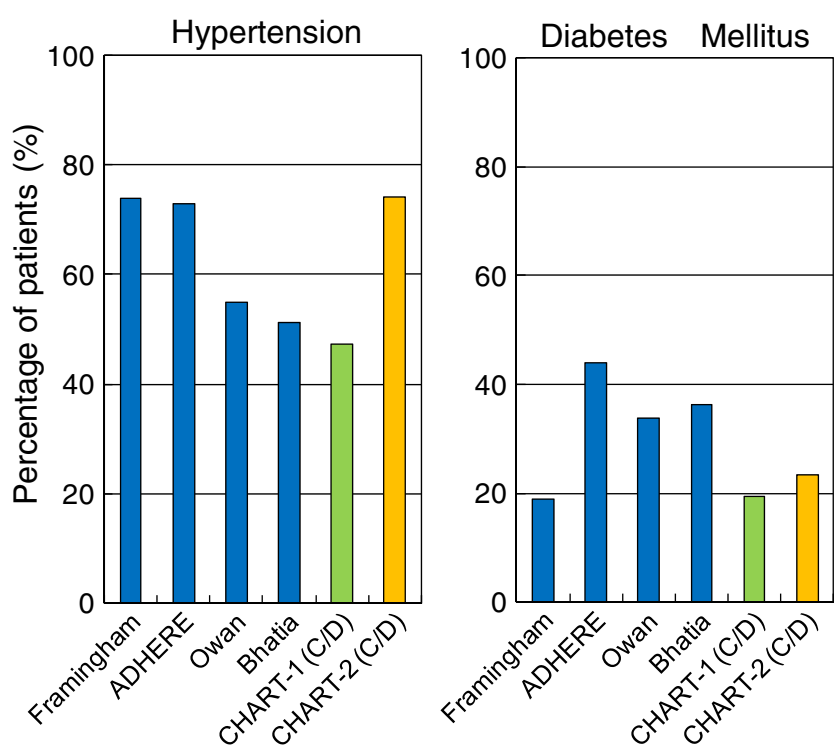

Fig. 15 Prevalence of hypertension and DM in Western patients and CHART patients [14]. Framingham, reference [65]; ADHERE, reference [66]; Owan, reference [68]; Bhatia, reference [69]; CHART-1, reference [8]; CHART-2, reference [14]

Primary results of the CHART-2 Study suggest that there has been a clear trend of increasing westernized etiology and risks among HF patients in Japan. Findings from the CHART-1 Study showed that HF patients with CAD had a poorer prognosis compared to those with non-ischemic cardiomyopathy [70]. Furthermore, it was predicted that the number of elderly HF patients will increase considerably in
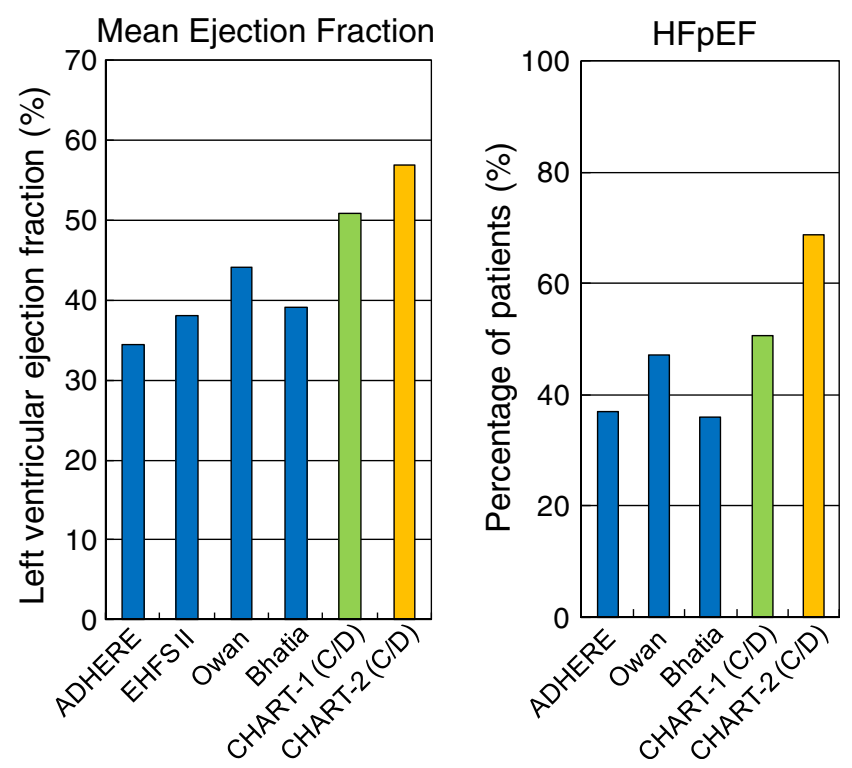

Fig. $16 \mathrm{EF}$ and prevalence of HF patients with preserved $\mathrm{EF}$ in Western patients and CHART patients [14]. Framingham, reference [65]; ADHERE, reference [66]; Owan, reference [68]; Bhatia, reference [69]; CHART-1, reference [8]; CHART-2, reference [14]; $\mathrm{HFpEF}$, heart failure patients with preserved ejection fraction

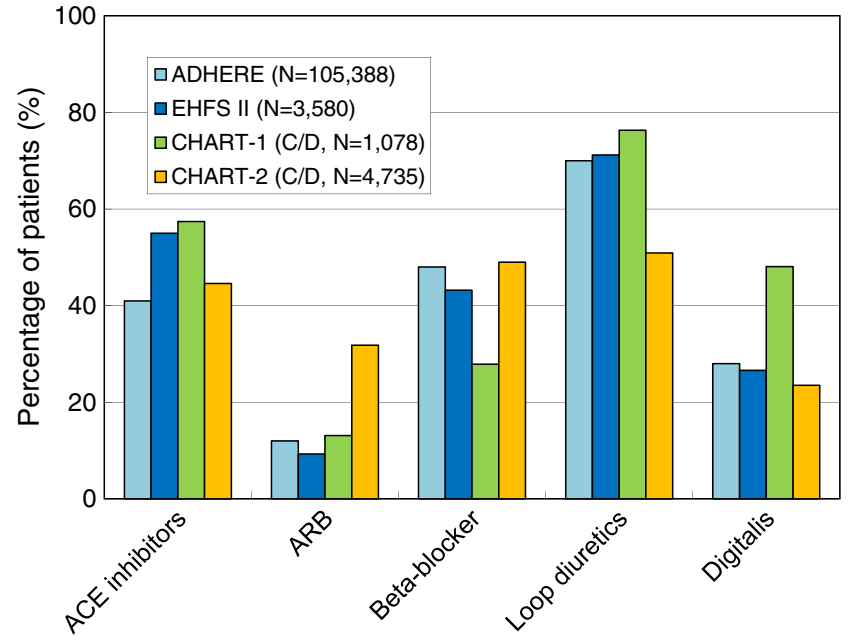

Fig. 17 Medication in patients with $\mathrm{HF}$ in Western patients and CHART patients [14]. ADHERE, reference [66]; EHFS II, reference [67]; CHART-1, reference [8]; CHART-2, reference [14]

the near future and these patients showed a significantly increased rate of cardiovascular events and mortality [9].

The CHART-2 Study revealed that patients in stage B or with $\mathrm{CAD}$ had a higher prevalence of cardiovascular risks, elevated BNP level and possible under-treatment of risk control, even though these patients did not show any overt HF symptoms. These findings clearly suggested that patients in stage $\mathrm{B}$ or with CAD were significantly vulnerable to developing $\mathrm{HF}$ in the future. We have to make an accurate risk stratification of all patients in stage $\mathrm{B}$ or with $\mathrm{CAD}$ and urge aggressive treatment in such patients (as well as in patients in stage $\mathrm{C}$ or $\mathrm{D}$ ) to improve the quality of life (QOL) and prognosis of all patients with CVD.

\section{Predictive, preventive, and personalized medicine in $\mathrm{HF}$ patients in Japan}

Predictive, preventive, and personalized medicine is a new approach in managing chronic diseases. HF is one of the diseases that need this new philosophy to reduce prevalence and to improve long-term outcomes and QOL. Given the future increase in the number of HF patients in Japan, management must implement 5 main strategies at each stage of development and progression of HF. Firstly, there must be an accurate prediction of individuals at a higher risk of disease progression or development of HF using biomarkers and prognostic risks (e.g., BNP, EF, GFR, and other authorized risk factors). Secondly, effective prevention of disease progression through appropriate treatments based on evidence-based guidelines is necessary. Thirdly, optimally personalized treatments (especially in elderly individuals, who form the majority of HF patients) are 
required. Fourthly, we need a lifelong approach for preventing the development of $\mathrm{HF}$ and caring for $\mathrm{HF}$ patients. CVD or HF usually needs a long time to develop; but, atherosclerosis starts to develop early in youth or even in childhood. Finally, the translation of genomic medicine (including gene expression, proteomics, metabolomics, molecular imaging) into a prospective personalized health plan is one of the promising strategies in the near future. Subsets of such approaches are available in cardiology, but these issues are beyond the scope of this contribution.

\section{Conclusions and outlook}

In Japan, a rapidly aging population and westernization of cardiovascular risks have led to an increase in the number of patients with CVD and HF. These trends may contribute in progression of CVD and further deteriorate the prognosis of such patients.

Given the progressive nature of the disease, an appropriate prospective approach is needed in the management of HF. Patients at a higher risk of developing HF must be predicted using biomarkers and other prognostic risk factors. Effective prevention of HF in Japan includes the strict control of westernized risks based on clinical guidelines to reduce the development of CAD, risk stratification of patients in stage $\mathrm{B}$ or those with $\mathrm{CAD}$, and delaying the stage progression of CVD with personalized medical or surgical treatment. The number of elderly patients with CVD or HF has been increasing. Hence, we must urge lifelong risk management in the general population as well. In addition, we need further studies to clarify the pathophysiology of HF with preserved EF and to determine novel risks that exacerbate the severity of CVD and HF. Predictive, preventive, and personalized medicine must be appropriately applied in patients with CVD or HF as well as in those at future risk of such diseases.

\section{Conflict of interest None.}

\section{References}

1. Chronic diseases, World Health Organization. URLhttp://www. who.int/topics/chronic_diseases/en/

2. Golubnitschaja $\mathrm{O}$, editor. Predictive diagnostics and personalized treatment: dream or reality? NewYork: Nova Science Publishers Inc; 2009.

3. Dupree CS. Primary prevention of heart failure: an update. Curr Opin Cardiol. 2010;25:478-83.

4. Roger VL, Go AS, Lloyd-Jones DM, Adams RJ, Berry JD, Brown TM, et al. American Heart Association Statistics Committee and Stroke Statistics Subcommittee. Heart disease and stroke statistics
2011 update: a report from the American Heart Association. Circulation. 2011;123:e18-e209.

5. Mendez GF, Cowie MR. The epidemiological features of heart failure in developing countries: a review of the literature. Int $\mathbf{J}$ Cardiol. 2001;80:213-9.

6. Ueshima H. Explanation for the Japanese paradox: prevention of increase in coronary heart disease and reduction in stroke. J Atheroscler Thromb. 2007;14:278-86.

7. Vital statics in Japan. Vital and Health Statistics Division, Statistics and Information Department, Minister's Secretariat, Ministry of Health, Labour and Welfare. URL http://www.e-stat. go.jp/SG1/estat

8. Shiba N, Watanabe J, Shinozaki T, Koseki Y, Sakuma M, Kagaya $\mathrm{Y}$, et al. Analysis of chronic heart failure registry in the Tohoku district: third year follow-up. Circ J. 2004;68:427-34.

9. Shiba N, Shimokawa H. Chronic heart failure in Japan: implications of the CHART studies. Vasc Health Risk Manag. 2008;4:103-13.

10. Hunt SA, Abraham WT, Chin MH, Feldman AM, Francis GS, Ganiats TG, et al. 2009 focused update incorporated into the ACC/AHA 2005 guidelines for the diagnosis and management of heart failure in adults: a report of the American College of Cardiology Foundation / American Heart Association task force on practice guidelines developed in collaboration with the International Society for Heart and Lung Transplantation. J Am Coll Cardiol. 2009;53:e1-e90.

11. Task Force for Diagnosis and Treatment of Acute and Chronic Heart Failure 2008 of European Society of Cardiology, Dickstein K, Cohen-Solal A, Filippatos G, McMurray JJ, Ponikowski P, et al. ESC guidelines for the diagnosis and treatment of acute and chronic heart failure 2008. Eur Heart J. 2008;29:2388-442.

12. Arnold JM, Howlett JG, Dorian P, Ducharme A, Giannetti N, Haddad H, et al. Canadian Cardiovascular Society consensus conference recommendations on heart failure update 2007: prevention, management during intercurrent illness or acute decompensation, and use of biomarkers. Can J Cardiol. 2007;23:21-45.

13. Heart Failure Society of America. Executive summary: HFSA 2006 comprehensive heart failure practice guideline. J Card Fail. 2006; $12: 10-38$.

14. Shiba N, Nochioka K, Miura M, Kohno H, Kohno H, CHART-2 Investigators. Trend of westernization of etiology and clinical characteristics of heart failure patients in Japan. Circ J. 2011;75:823-33.

15. National Institute of Population and Social Security Research. (in Japanese) URL http://www.ipss.go.jp/syoushika/tohkei/Popular/ Popular2011.asp?chap $=0$

16. Erlinger TP, Appel LJ. Dietary patterns and coronary heart disease. In: Marmot M, Elliott P, editors. Coronary heart disease epidemiology: from aetiology to public health. 2nd ed. Oxford: Oxford University Press; 2005. p. 207-19.

17. Egusa G, Yamane K. Lifestyle, serum lipids and coronary artery disease: comparison of Japan with the United States. J Atheroscler Thromb. 2004;11:304-12.

18. The National Nutrition Survey of Japan. (in Japanese) URL http:// www.mhlw.go.jp/bunya/kenkou/kenkou_eiyou_chousa.html

19. Ueshima H. Changes in dietary hibits, cardiovascular risk factors and mortality in Japan. Acta Cardiol. 1990;45:311-27.

20. Morris JN, Haskell WL. Exercise versus heart attack: history of a hypothesis. Addendum to chapter 19. In: Marmot M, Elliott P, editors. Coronary heart disease epidemiology: From aetiology to public health. 2nd ed. Oxford: Oxford University Press; 2005. p. 275-90.

21. Shibata Y, Hayasaka S, Yamada T, Goto Y, Ojima T, Ishikawa S, et al. Physical activity and cardiovascular disease in Japan: the Jichi Medical School Cohort Study. J Epidemiol. 2010;20:225-30. 
22. He FJ, MacGregor GA. A comprehensive review on salt and health and current experience of worldwide salt reduction programmes. J Hum Hypertens. 2009;23:363-84.

23. Martiniuk AL, Lee CM, Lawes CM, Ueshima H, Suh I, Lam TH, et al. Hypertension: its prevalence and population-attributable fraction for mortality from cardiovascular disease in the Asia-Pacific region. J Hypertens. 2007;25:73-9.

24. Lawes CM, Rodgers A, Bennett DA, Parag V, Suh I, Ueshima H, et al. Blood pressure and cardiovascular disease in the Asia Pacific region. J Hypertens. 2003;21:707-16.

25. Woodward M, Zhang X, Barzi F, Pan W, Ueshima H, Rodgers A, et al. The effects of diabetes on the risks of major cardiovascular diseases and death in the Asia-Pacific region. Diabetes Care. 2003;26:360-6.

26. Wild S, Roglic G, Green A, Sicree R, King H. Global prevalence of diabetes: estimates for the year 2000 and projections for 2030 . Diabetes Care. 2004;27:1047-53.

27. National Survey on Diabetes Mellitus Prevalence in Japan. (in Japanese) URL http://www.mhlw.go.jp/houdou/2008/12/dl/h12255d.pdf and http://www.mhlw.go.jp/shingi/2004/03/s0318-15.html (access on March 9, 2011)

28. Ueshima H, Sekikawa A, Miura K, Turin TC, Takashima N, Kita $\mathrm{Y}$, et al. Cardiovascular disease and risk factors in Asia: a selected review. Circulation. 2008;118:2702-9.

29. Ueshima H, Tatara K, Asakura S, Okamoto M. Declining trends in blood pressure level and the prevalence of hypertension, and changes in related factors in Japan. 1956-1980. J Chron Dis. 1987;40:137-47.

30. Nakamura K, Okamura T, Hayakawa T, Hozawa A, Kadowaki T, Murakami Y, et al. The proportion of individuals with obesityinduced hypertension among total hypertensives in a general Japanese population: NIPPON DATA 80,90. Eur J Epidemiol. 2007;22:691-8

31. Shiraishi J, Kohno Y, Sawada T, Nishizawa S, Arihara M, Hadase $\mathrm{M}$, et al. Relation of obesity to acute myocardial infarction in Japanese patients. Differences in gender and age. Circ J. 2006;70:1525-30.

32. Woodward M, Lam TH, Barzi F, Patel A, Gu D, Rodgers A, et al. Smoking, quitting, and the risk of cardiovascular disease among women and men in the Asia-Pacific region. Int J Epidemiol. 2005;34:1036-45.

33. Martiniuk AL, Lee CM, Lam TH, Huxley R, Suh I, Jamrozik K, et al. The fraction of ischaemic heart disease and stroke attributable to smoking in the WHO Western Pacific and South-East Asian region. Tabacco. Control. 2006;15:181-8.

34. Ueshima H. Trends in Asia. In: Marmot M, Elliott P, editors. Coronary heart disease epidemiology: from aetiology to public health. 2nd ed. Oxford: Oxford University Press; 2005. p. 102-11.

35. Noda H, Iso H, Irie F, Sairenchi T, Ohtaka E, Ohta H. Gender difference of association between LDL cholesterol concentrations and mortality from coronary heart disease amongst Japanese: the Ibaraki Prefectural Health Study. J Intern Med. 2010;267:576-87.

36. Arai H, Yamamoto A, Matsuzawa Y, Saito Y, Yamada N, Oikawa S, et al. Serum lipid survey and its recent trend in the general Japanese population in 2000. J Atheroscler Thromb. 2005;12:98-106.

37. Ueshima H, Iida M, Shimamoto T, Konishi M, Tanigaki M, Doi $\mathrm{M}$, et al. Dietary intake and serum total cholesterol level: their relationship to different lifestyle in several Japanese populations. Circulation. 1982;66:519-26.

38. Nakamura Y, Hozawa A, Turin TC, Takashima N, Okamura T, Hayakawa T, et al. NIPPON DATA80 Research Group. Dietary habits in middle age and future changes in activities of daily livingNIPPON DATA80. Gerontology. 2009;55:707-13.

39. Roger VL, Jacobsen SJ, Weston SA, Bailey KR, Kottke TE, Frye RL. Trends in heart disease deaths in Olmsted County, Minnesota, 1979-1994. Mayo Clin Proc. 1999;74:651-7.
40. McGovern PG, Jacobs Jr DR, Shahar E, Arnett DK, Folsom AR, Blackburn $\mathrm{H}$, et al. Trends in acute coronary heart disease mortality, morbidity, and medical care from 1985 through 1997: the Minnesota heart survey. Circulation. 2001;104:19-24.

41. Kodama K, Sasaki H, Shimizu Y. Trend of coronary heart disease and its relationship to risk factors in a Japanese population: a 26year follow-up, Hiroshima/Nagasaki Study. Jap Circ J. 1990;54:414-21.

42. Kitamura A, Sato S, Kiyama M, Imano H, Iso H, Okada T, et al. Trends in the incidence of coronary heart disease and stroke and their risk factors in Japan, 1964 to 2003. The Akita-Osaka Study. J Am Coll Cardiol. 2008;52:71-9.

43. Kubo M, Kiyohara Y, Kato I, Tanizaki Y, Arima H, Tanaka K, et al. Trends in the incidence, mortality, and survival rate of cardiovascular disease in a Japanese community: the Hisayama Study. Stroke. 2003;34:2349-54.

44. Van der Bom JG, Grobbee DE. Risk factors in the elderly. In: Marmot M, Elliott P, editors. Coronary heart disease epidemiology: from aetiology to public health. 2nd ed. Oxford: Oxford University Press; 2005. p. 606-26.

45. A report from the Tokyo Fire Department on January 5, 2011. (in Japanese) URL http://www.tfd.metro.tokyo.jp/hp-kouhouka/pdf/ 230105.pdf

46. Miettinen TA, Pyörälä K, Olsson AG, Musliner TA, Cook TJ, Faergeman O, et al. Cholesterol-lowering therapy in women and elderly patients with myocardial infarction of angina pectoris: findings from the Scandinavian Simvastatin Survival Study (4S). Circulation. 1997;96:4211-8.

47. Downs JR, Clearfield M, Weis S, Whitney E, Shapiro DR, Beere PA, et al. Primary prevention of acute coronary events with lovastatin in men and women with average cholesterol levels: results of AFCAPS/ TexCAPS. Air Force/Texas Coronary Atherosclerosis Prevention Study. JAMA. 1998;279:1615-22.

48. Kannel WB, Gordan T. Evaluation of cardiovascular risk in the elderly: the Framingham study. Bull N Y Acad Med. 1978;54:573-91.

49. MacMahon S, Rodgers A. The effects of blood pressure reduction in older patients: an overview of five randomized controlled trials in elderly hypertensives. Clin Exp Hypertens. 1993; 15:967-78.

50. Mulrow CD, Cornell JA, Herrera CR, Kadri A, Farnett L, Aguilar C. Hypertension in the elderly: implications and generalizability of randomized trials. JAMA. 1994;272:1932-8.

51. Beckett NS, Peters R, Fletcher AE, Staessen JA, Liu L, Dumitrascu D, et al. HYVET Study Group. Treatment of hypertension in patients 80 years of age or older. N Engl J Med. 2008;358:1887-98.

52. Houterman S, Boshuizen HC, Verschuren WM, Giampaoli S, Nissinen A, Menotti A, et al. Predicting cardiovascular risk in the elderly in different European countries. Eur Heart J. 2002;23:294-300.

53. Hermanson B, Hermanson GS, Kronmal RA, Gersh BJ. Beneficial sex-year outcome of smoking cessation in older men and women with coronary artery disease. Results from the CASS registry. N Engl J Med. 1988;319:1365-9.

54. Psaty BM, Furberg CD, Kuller LH, Bild DE, Rautaharju PM, Polak JF, et al. Traditional risk factors and subclinical disease measures as predictors of first myocardial infarction in older adults: the Cardiovascular Health Study. Arch Intern Med. 1999;159:1339-47.

55. Kuusisto J, Mykkänen L, Pyörälä K, Laakso M. NIDDM and its metabolic control predict coronary heart disease in elderly subjects. Diabetes. 1994:43:960-7.

56. Emerging Risk Factors Collaboration, Sarwar N, Gao P, Seshasai SR, Gobin R, Kaptoge S, et al. Fasting glucose concentration, diabetes mellitus, and risk of vascular disease: a collaborative meta-analysis of 102 prospective studies. Lancet. 2010;375:2215-22.

57. Burt VL, Whelton P, Roccella EJ, Brown C, Cutler JA, Higgins $\mathrm{M}$, et al. Prevalence of hypertension in the US adult population: 
results from the Third National Health and Nutrition Examination Survey, 1988-1991. Hypertension. 1995;25:305-13.

58. Shiba N, Nochioka K, Kohno H, Matsuki M, Takahashi J, Tada T, et al. Emerging problems of heart failure practice in Japanese women: lessons from the CHART study. Circ J. 2008;72:2009-14.

59. Shiba N, Shimokawa H. Chronic kidney disease and heart failureBidirectional close link and common therapeutic goal. J Cardiol. 2011;57:8-17.

60. Hillege HL, Nitsch D, Pfeffer MA, Swedberg K, McMurray JJ, Yusuf $\mathrm{S}$, et al. Renal function as a predictor of outcome in a broad spectrum of patients with heart failure. Circulation. 2006;113:671-8.

61. Lopez AD, Shibuya K, Rao C, Mathers CD, Hansell AL, Held LS, et al. Chronic obstructive pulmonary disease: current burden and future projections. Eur Respir J. 2006;27:397-412.

62. Mazza A, Zamboni S, Rubello D, Schiavon L, Zorzan S, Casiglia E. Chronic obstructive pulmonary disease and cardiovascular mortality in elderly subjects from general population. Blood Pressure. 2010;19:67-74.

63. Kjøller E, Køber L, Iversen K, Torp-Pedersen C, Trace Study Group. Importance of chronic obstructive pulmonary disease for prognosis and diagnosis of congestive heart failure in patients with acute myocardial infarction. Eur J Heart Fail. 2004;6:71-7.

64. Asanuma H, Kitakaze M. The largest cohort study opens a new era for the management of heart failure in Japan. Circ J. 2011;75:775-76.
65. Ho KK, Anderson KM, Kannel WB, Grossman W, Levy D. Survival after the onset of congestive heart failure in Framingham Heart Study. Circulation. 1993;88:107-15.

66. Adams Jr KF, Fonarow GC, Emerman CL, LeJemtel TH, Costanzo MR, Abraham WT, et al. Characteristics and outcomes of patients hospitalized for heart failure in the United States: rationale, design, and preliminary observations from the first 100,000 cases in the Acute Decompensated Heart Failure National Registry (ADHERE). Am Heart J. 2005;149:209-16.

67. Nieminen MS, Brutsaert D, Dickstein K, Drexler H, Follath F, Harjola VP, et al. EuroHeart Failure Survey II (EHFS II): a survey on hospitalized acute heart failure patients: description of population. Eur Heart J. 2006;27:2725-36.

68. Owan TE, Hodge DO, Herges RM, Jacobsen SJ, Roger VL, Redfield MM. Trends in prevalence and outcome of heart failure with preserved ejection fraction. $\mathrm{N}$ Engl $\mathrm{J}$ Med. 2006;355:251-9.

69. Bhatia RS, Tu JV, Lee DS, Austin PC, Fang J, Haouzi A, et al. Outcome of heart failure with preserved ejection fraction in a population-based study. N Engl J Med. 2006;355:260-9.

70. Shiba N, Watanabe J, Shinozaki T, Koseki Y, Sakuma M, Kagaya Y, et al. Poor prognosis of Japanese patients with chronic heart failure following myocardial infarction-comparison with nonischemic cardiomyopathy. Circ J. 2005;69:143-9. 